\title{
INSPEÇÃO SANITÁRIA E CRITÉRIO DE JULGAMENTO DA CISTICERCOSE BOVINA CALCIFICADA. INFECÇĀO LEVE*
}

\author{
SANITARY INSPECTION AND JUDGEMENT CRITERION OF \\ CALCIFIED BOVINE CYSTICERCOSIS. LOW INFECTIONS.
}

\author{
Lauro Vicente Campello Rodrigues*
}

\section{RESUMO}

O experimento objetivou avaliar os riscos para a saúde pública da cisticercose e da teníase atraves da infecção da carne de bovinos pelo Cysticercus bovis e a Taeniarhyncus saginatus (Taenia saginata GOEZE, 1782). A pesquisa, ao nível de matadouro no Estado do Rio Grande do Sul, concentrou-se no grau de "infecção leve", ou seja, na constatação de um único cisticerco calcificado, no conjunto de órgãos, vísceras e carcaças, buscando-se a existência de outros cisticercos, especialmente os vivos, através do fatiamento de massas musculares dos segmentos mais valorizados da carcaça (filé mignon, filé de lombo, alcatra, coxão mole, coxão duro, patinho e lagarto). Das 16 carcaças utilizadas no experimento, 5 delas $(31,25 \%)$ acusaram presença de cisticerco em um de seus cortes nobres fatiados, sendo que em 2 delas $(12,5 \%)$ os cisticercos eram vivos e, em $3(18,75 \%)$, eram degenerados (calcificados). O experimento, inclusive calcado em literatura disponivel e na regulamentação a propósito de diversos países, permitiu recomendar à Divisão de Inspeção de Produtos de Origem Animal, do Ministério da Agricultura e Reforma Agrária, a revisão do Art. no 176 , Parágrafo $2^{\circ}$, Inciso 3 , do Regulamento de Inspeçāo Industrial e Sanitária de Produtos de Origem Animal, que permite o aproveitamento para o consumo de carcaças que apresentam um único cisto já calcificado, sem qualquer tratamento prévio.

\section{SUMMARY}

The experiment aimed to evaluate the risks to the public health caused by Cysticercosis and taeniase due to bovine meat infection by Cysticercus bovis and Taeniarhyncus saginatus (Taenia saginata, Goeze, 1782).
The research focused on the light infection level, concerning it on a slaughterhouse basis, in Rio Grande do Sul state, Brazil. The research was concerned in finding a unique dead cysticercus while searching for other cysticerci, specially viable ones, through the slicing of the most valuable muscular mass of the carcass (hind cuts). Five $(31,25 \%)$ out of the 16 carcasses used in the experiment indicated the presence of cysticercus in one of their sliced noble cuts, viable cysticerci were found in the other 3 lasting carcasses $(18,75 \%)$. The experiment, based on available literature and several countries regulations, allowed us to recommend to the "Divisão de Inspeção de Produtos de Origem Animal " of the Agriculture Ministry and Agrarian Reform the review over the article 176, paragraph 2, inc. 3 , of the " Industrial and Sanitary Inspection of Animal Products" regulation that permites the use of carcasses which have presented a single dead cyst for consumption without any previous treatment.

\section{INTRODUÇÃO}

Reconhecidamente a inspeção Sanitária de Carnes realizada em estabelecimentos caracterizados como matadouros-frigoríficos, desempenha atividades preventivas da mais alta relevância para a saúde pública ao afastar do mercado carnes impróprias para o consumo ou que possam ser potencialmente prejudiciais.

Dentre todas as alteraçōes em carnes bovinas submetidas a inspeçāo sanitária, em matadouros-frigoríficos sob Inspeção Federal no Rio Grande do Sul, a cisticercose ocupa o $1^{\circ}$ lugar em número de achados que determinam a retenção de carcaças (SERPA/RS).

Este fato é significativo e impõe a necessidade de se submeter essas carnes a tratamentos preventivos (pelo frio, calor ou salga), objetivando inviabilizar os cisticercos nelas presentes, e assim eliminar completamente

\footnotetext{
Parte de Dissertação de Mestrado apresentada pelo autor em 25/05/92, ao Curso de Pós-Graduação em Mzdicina Veterinária, do Centro de Ciências Médicas da Universidade Federal Fluminense. Rua Vital Brasil, 64, 24230-340 - NITERÓI-RJ.

* Médico Veterinário do Ministério da Agricultura, Mestre em Medicina Veterinária, área de concentração Higiene Veterinária e Processamento Tecnológico de Produtos de Origem Animal. Rua Floriano Peixoto, 1303, apartamento 108, 97015-372, Santa Maria-RS.
} 
os riscos dos consumidores contraírem a Taeniarhyncus saginatus por ingestāo de carnes mal passadas.

A importância desse procedimento é reconhecida por GINSBERG (1960), JURANEK et al (1976) e SANTOS (1984). Este último acrescenta que os procedimentos visando a detecção da cisticercose muscular nas carcaças de bovinos constituem uma das tarefas mais significativas para os especialistas em higiene da carne e que esta detecçāo durante a rotina post-mortem da inspeção sanitária em matadouros é a principal baliza para prevenir a transmissāo das teníases.

Não obstante ao reconhecimento da sua importância, a inspeção de carnes por si só não pode detectar todos os cisticercos presentes nas carnes visto que, por razōes de natureza estética e comercial, o inspetor normalmente não retalha todos os órgãos, vísceras e carcaças submetidos à inspeçāo de rotina ou posteriormente a ela.

Este fato é confirmado por MARSHBOOM et al (1960), DEWHIRST et al (1967), JURANEK et al (1976), RICKARD \& ADOLPH (1977), McCOOL (1979), que compararam em seus trabalhos o número de cisticercos detectados pelos procedimentos normais de rotina, com o número de cisticercos evidenciados por minucioso fatiamento dessas mesmas porções e de outras não rotineiramente examinadas em carcaças. Constataram eles, experimentalmente, que nos procedimentos normais de rotina de inspeção não foi possível detectar de 26,0 a $56,7 \%$ dos animais cisticercósicos em relação aos casos pesquisados.

A este propósito, DEPRÈS \& RUOSCH (1961); ABDUSSALAM (1974); WALTHER \& KOSKE (1980), enfatizaram que quanto mais leve o grau de infecção pelo C. bovis maior a possibilidade de passarem cisticercos sem ser detectados pelos procedimentos normais de rotina de inspeção.

Dissonando destas constataçōes, a legislação de inspeção de Carnes do Brasil, no Regulamento de Inspeçāo Industrial e Sanitária de Produtos de Origem Animal (RIISPOA, 1951), em seu Artigo 176, Parágrafo $2^{\circ}$, Inciso 3 , determina a liberaçāo para o consumo, sem qualquer tratamento preventivo, das carcaças bovinas que, submetidas a inspeção de rotina, tenham, acusado a presença mesmo de um único cisticerco calcificado (infecção leve).

A liberação ao consumo de carcaças bovinas dentro das condições descritas, contraria as constataçōes de SILVERMANN (1956), DEPRÈS \& RUOSCH (1961), JURANEK et al (1976), McCOOL (1979), Sgambati apud EUZEBY (1984), que comprovaram a presença de $\mathbf{C}$. bovis vivo e $\mathbf{C}$. bovis calcificado em carnes de um mesmo animal, significando isto que a constataçāo de um único cisto calcificado na rotina, nāo afasta a possibilidade da presença de cisto vivo em outra região do corpo não rotineiramente examinada.

Isto é preocupante quando se verifica que no
Rio Grande do Sul, no período compreendido entre 1980 e 1990, foram liberadas regulamentarmente para o consumo, sem qualquer tratamento prévio, 317.133 carcaças de bovinos caracterizados como infectados levemente (um único cisticerco calcificado, no conjunto de órgãos, vísceras e carcaças submetidos ao exame de rotina de inspeção). Este número representa $76,16 \%$ de todos os casos de cisticercose detectados no Rio Grande do Sul no citado período. Dados estatísticos do Ministério da Agricultura e Reforma Agrária, registram que, no ano de 1986, em matadouros frigoríficos sob Inspeção Federal no Brasil, se detectou 146.981 casos de cisticercose bovina. Considerando que $76,16 \%$ desse total são bovinos levemente infectados, temos que: 111.940 carcaças foram liberadas ao consumo sem qualquer tratamento preventivo à cisticercose.

Merecem considerações, ademais, quanto a "infecção leve",os trabalhos de GINSBERG (1958), McMANUS (1963), NADZHAROVL et al (1989), que demonstraram poderem os bovinos nascer albergando $C$. bovis em suas massas musculares. Assim sendo, o consumo de carne de vitelo, inspecionada nos termos do Art. 176, Parágrafo $4^{\circ}$, pode levar risco aos consumidores, já que determina, como inspeção de rotina para bovinos com menos de 6 meses de idade, apenas o exame supeficial do coração e de outras superfícies musculares normalmente visiveis. Sobre este assunto, LAZZARO (1961) diz que cometem erro os inspetores que sustentam que examinando visualmente e palpando o coração inteiro se possa detectar o que está parasitado. Registros de GINSBERG (1958) dão conta que o regulamento de inspeção de carnes do Quênia se modificou neste particular e determina que se apliquem os mesmos procedimentos de inspeção de rotina para cisticercose a todos os bovinos, independente da idade ao abate.

É de admitir-se, por outra, que a adoção de tratamentos preventivos para as carnes infectadas levemente levarão gradativamente à diminuição das rejeições e dos prejuízos econômicos delas decorrentes e, sobretudo, contribuirão para afastar os danos levados às populações pela teníase e/ou cisticercose humana, de grande ressonância na área médica.

Objetivando salvaguardar a saúde de seus consumidores e com isto minimizar os problemas econômico-sociais resultantes do complexo teníase/cisticercose, alguns países como Argentina, Estados Unidos da América, França, Uruguai e Alemanha, adequaram suas legislaçōes de inspeção de carnes às evidências científicas no que diz respeito a tratamentos preventivos para carnes de bovinos que, ao exame de rotina de inspeção, tenham acusado mesmo um único cisticerco calcificado, ou seja a forma mais leve de cisticercose possivel de ser detectada pelos procedimentos normais de rotina de inspeção.

Em sendo reconhecidamente o trabalho realizado pela Inspeção Sanitária de Carnes de natureza pre- 
ventiva em Saúde Pública, é preciso em nosso país que se tome consciência da importância social e econômica que representa a adoção, pela regulamentação, de tratamento preventivo adequado para carnes bovinas caracterizadas como infectadas levemente pelo $\mathrm{C}$. bovis. Assim agindo, dar-se-á passo significativo no sentido de interromper mais efetivamente $\mathrm{O}$ ciclo biológico da $\mathrm{T}$. saginatus e proteger as populaçōes desta temida zoonose.

Para este efeito, impõe-se a necessidade de uma revisão da regulamentação da espécie - RIISPOA (1951), da DIPOA - Ministério da Agricultura e Reforma Agrária, fato que constitui um dos objetivos deste experimento.

Assim sendo, objetiva-se frente ao achado de um único cisticerco calcificado nas linhas de inspeçăo de rotina, pesquisar a concomitância de outros cisticercos nos cortes mais valorizados da carcaça em especial a presença de cistos vivos.

\section{MATERIAL E MÉTODOS}

O trabalho foi desenvolvido no Matadouro-Frigorífico Swift Armour S.A.- SIF-7, na cidade de Santana do Livramento, Estado do Rio Grande do Sul, nos meses de abril e maio do ano de 1991. Contou-se com o apoio de quatro Médicos Veterinários, Inspetores de carnes do Ministério da Agricultura e Reforma Agrária, lotados na Inspeção Federal do citado estabelecimento.

O material utilizado nesta pesquisa contou com os sete cortes nobres retirados de trinta traseiros tipo serrote de dezesseis carcaças bovinas, em uma delas foi retirado apenas o traseiro esquerdo e noutra o traseiro direito, cujos órgãos e vísceras correspondentes (coração, cabeça, língua e esôfago), após a inspeção de rotina, tiveram um único cisticerco calcificado e que, desviados para inspeção final, nada mais evidenciaram, após minuciosa reinspeçāo para cisticercose (por visualização, palpação e fatiamento dos órgãos e vísceras citados). Foram realizadas, também, inspeçōes nas carcaças através de visualização e incisões no diafragma e seus pilares, músculos peitorais e do pescoço.

As dezesseis carcaças selecionadas para realização do experimento foram obtidas dentre 230 novilhos (machos castrados), abatidos na faixa etária de 2 a 6 anos, e de 172 fêmeas na faixa etária de 5 a 8 anos. Todos estes bovinos eram mestiços de raças européias, com predominância de sangue Hereford, criados extensivamente em quinze propriedades de sete municípios do estado do Rio Grande do Sul.

Deste abate, foram selecionadas nove carcaças de machos e sete carcaças de fêmeas.

Diariamente, após o término dos trabalhos de abate, a partir de anotações oficiais do Inspetor Veterinário, dentre os lotes abatidos, foram destacados aque- les que apresentaram índices de cisticercose acima de $5,49 \%$. Desta forma, trabalhou-se sempre com carcaças de lotes de áreas endêmicas, quanto à cisticercose, para o estado do Rio Grande do Sul (Boletim Estatístico 1986-1987-1988-SERPA/MA/RS).

A seleção das carcaças, dentro dos lotes previamente escolhidos, era exequivel, porque todas as carcaças cujos órgãos ou visceras correspondentes apresentaram infecção leve ou moderada para cisticercose, na linha de rotina de inspeção, receberam, por parte do Médico Veterinário, no Departamento de Inspeção Final, identificação através de etiqueta de sequestro numerada, contendo data do abate, curral de origem, número do lote, e órgão ou víscera de rotina onde ocorreu o cisticerco degenerado, além de idade estimada pela arcada dentária. Esta etiqueta era afixada ao antebraço da carcaça sequestrada, e possuia uma homônima picotada $e$ destacável com o mesmo número e anotações feitas anteriormente pelo Médico Veterinário. Assim manteve-se sempre o controle sobre a identidade das carcaças retidas na câmara de sequestro.

A partir dos dados da etiqueta homônima, dentro da câmara de sequestro, identificou-se e separou-se, em trilho específico, acrescentando-se mais um rótulo de interditado nas dimensões de $40 \times 10 \mathrm{~cm}$, nas carcaças que proporcionaram os sete cortes para fatiamento.

Após 24 horas de resfriamento, as carcaças foram liberadas do seqüestro e deslocadas por trilhamento ate a sala de desossa do estabelecimento, onde cada meia carcaça foi dividida em três cortes comerciais: quarto dianteiro; ponta de agulha e traseiro serrote (Portaria MARA no 5 DOU de 18/11/88 - Seção I). Após averiguação visual de todo o traseiro serrote, não foi encontrado cisticerco algum, procedendo-se a retirada dos sete cortes nobres, a saber: filé-mignon; filé-de-lombo; alcatra; coxão mole; coxão duro; patinho e lagarto.

O despostamento foi realizado através do uso de faca apropriada, estando o traseiro dependurado pelo garrão durante todo o processo, sempre identificando-se as bases musculares correspondentes a cada um dos cortes descritos. Uma vez removidos eram colocados em recipientes identificados, um para receber os cortes da meia carcaça direita e outro os cortes da meia carcaça esquerda. Isto feito, foram deslocadas para o interior da câmara de seqüestro, onde, em mesa inox $(2,0 \mathrm{~m} \times 1,0 \mathrm{~m})$ e sob luz artificial de intensidade de 500 lux, os cortes foram fatiados, um a um, no mesmo sentido da fibra muscular. As porções resultantes dos fatiamentos, mostravam espessura de aproximadamente $3 \mathrm{~mm}$, o suficiente para detecção, visual e por palpação, de cisticerco.

Fatiou-se em média, a cada dia, os sete cortes de uma carcaça.

Sempre que detectou-se a presença de cisticer$\mathrm{co}$, avaliou-se visualmente se vivo ou degenerado (calcificado), tendo-se o cuidado de anotar individualmente 
em que corte estava presente; além de registrar o achado em foto e diapositivos e, quando vivo, averiguou-se suas dimenções através de paquímetro.

\section{RESULTADOS}

Das 16 carcaças utilizadas no experimento, e que haviam acusado apenas um cisticerco degenerado na cabeça ou no coração, 5 delas $(31,25 \%)$ acusaram a presença de cisticerco em um de seus cortes nobres fatiados, sendo que em 2 delas $(12,5 \%)$ os cisticercos eram vivos e em $3(18,75 \%)$, eram calcificados

Ao fatiamento dos 30 cortes conhecidos como alcatra evidenciou-se, em um deles, um cisticerco vivo com $1 \mathrm{~mm}$ de diâmetro e em outro um cisticerco degenerado (calcificado), representando estes achados $6,66 \%$ em relação ao total o corte fatiado.

Ao fatiamento dos 30 cortes conhecidos como coxão-mole, evidenciou-se, em um deles, um cisticerco vivo com $3 \mathrm{~mm}$ de diâmetro, representando este achado $3,33 \%$ em relaçāo ao total do corte fatiado.

Ao fatiamento dos 30 cortes conhecidos como coxão-duro e patinho, evidenciou-se dois cisticercos degenerados (calcificados), um no coxão-duro e outro no patinho, representando este achado $3,33 \%$ em relação ao total de cada corte fatiado.

Nos cortes conhecidos comercialmente como filé-mignon, filé-de-lombo e lagarto, não foi evidenciada presença de cisticercos durante seus fatiamentos.

\section{DISCUSSÃO}

Atualmente a legislação brasileira, RIISPOA (1951), determina a liberação para o mercado consumidor, sem prévio tratamento, das carcaças bovinas que, após submetidas a inspeção de rotina de carnes, sejam caracterizadas como infectadas levemente para cisticercose (um único cisticerco calcificado no conjunto de orgāos e vísceras ou na carcaça).

Segundo JURANEK et al (1976), duas hipóteses, não confirmadas, têm sido usadas para evitar o congelamento dessas carnes:

- a primeira sustenta que quando se detecta um único cisticerco calcificado, não há razão para congelamento da carcaça após a extirpação do cisto;

- a segunda hipótese diz que todos os cisticercos na carcaça têm uma expectativa de vida, e portanto a detecção de um único cisticerco calcificado indica que algum outro cisto na carcaça deve também estar calcificado.

Diante dos resultados obtidos nesta investigação, estas duas hipóteses, que são argumentos para evitar o tratamento preventivo pelo frio ou outro método de saneamento de carcaças bovinas levemente infectadas, nāo encontram sustentação.
Os resultados deste trabalho são similares aos obtidos por JURANEK et al (1976) que utilizaram 11 carcaças de bovinos que, na linha de rotina de inspeção de carne, acusaram um único cisticerco calcificado no coração ou na cabeça e que através do fatiamento da mesma região anatômica por nós pesquisada (traseiro) evidenciaram que uma das carcaças albergava um cisticerco vivo, representando este achado $9,9 \%$ do total das carcaças. Detectaram, ainda, uma outra carcaça com cisticerco calcificado na mesma região anatômica em pesquisa.

Este trabalho justifica o conceito expendido por JURANEK et al (1976) quando considera correta a modificação introduzida no regulamento de inspeção de carnes Norte-Americano, a partir de 1970, determinando que carnes que acusem um único cisticerco calcificado ou vivo, antes de serem liberadas ao consumo devem ser tratadas pelo frio $\left(-10^{\circ} \mathrm{C}\right.$ por 10 dias) ou pelo calor (temperatura não inferior a $56^{\circ} \mathrm{C}$ ).

Este trabalho dá suporte às observações de SILVERMANN (1956), DEPRÉS \& RUOSCH (1961), McCOOL (1979) e Sgambati apud EUZEBY (1984), que registraram a ocorrência de cisticerco vivo e degenerado (calcificado) em carnes de um mesmo animal, e comprova o fato que, em caso de detecção de um único cisticerco degenerado pela inspeção de rotina de carcaças, órgãos e vísceras, não está afastada a possibilidade de presença de cisticerco vivo em outras porções musculares não rotineiramente examinadas.

Este trabalho comprova, inclusive, o acerto das recomendações de THAKUR (1984), quando diz que a legislação de carnes deve prever o tratamento adequado para carnes que acusem cisticerco degenerado porque se tem encontrado cisto vivo e degenerado em um mesmo animal.

A presente pesquisa está de acordo também, com as observações de DEWHIRST et al (1967), ABDUSSALAM (1974), RICKARD \& ADOLPH (1977), MCCOOL (1979), WALTHER \& KOSKE (1980), CÔRTES J.A. (1984), ACHA \& SZIFRES e Organizacion Mundial De La Salud apud UNGAR (1990), que registraram a inviabilidade da inspeção de rotina detectar todos os cisticercos presentes nas carnes dos animais infectados.

Com base nos resultados do presente experimento, são corretos os procedimentos dos regulamentos de inspeção de carnes da Argentina, Estados Unidos da América, França, Uruguai e Alemanha, que. determinam tratamento pelo frio para carnes de bovinos infectados levemente por cisticercose (um único cisticerco calcificado detectado ao nível de rotina de inspeção de carnes), antes de serem liberadas ao consumo.

Este trabalho não concorda com Bertolini apud SGAMBATI (1959), visto que 3 das carcaças que acusaram cisticercos nos sete cortes em pesquisa eram de animais que apontaram na linha de rotina, somente cisticercos na cabeça ao passo que este pesquisador diz 
que em caso de não se detectar na rotina cisticerco no coração, pode-se inferir que no resto do corpo não existe cisticerco algum.

O presente trabalho não dá sustentação aos procedimentos regulamentares (RIISPOA - 1951), adotados pelo Brasil para carnes de bovinos caracterizadas como infectadas levemente (um único cisticerco calcificado no conjunto de órgãos e vísceras ou na carcaça) e que são atualmente levadas ao mercado consumidor sem qualquer tratamento preventivo que elimine $o$ risco do homem contrair a teníase por ingestão de carne mal passada.

Dados do Ministério da Agricultura no Rio Grande do Sul, mostram que, no período de 1981 a $1990,317.133$ carcaças de bovinos infectados levemente $(3,43 \%$ do total abatido) foram liberadas para o consumo humano levando risco do consumidor contrair a teníase por ingestão de carnes mal passadas. Esta preocupação se acentua na medida que este experimento evidenciou cisticerco vivo nos cortes conhecidos comercialmente como coxão mole e alcatra, que por sua natureza são considerados tenros e saborosos pelo consumidor, e não requerem maiores temperaturas para evidenciarem suas características organolépticas.

\section{CONCLUSÕES}

Conclui-se que a presença de um único cisticerco calcificado no conjunto de órgãos, vísceras e carcaças na rotina de inspeção, não isenta a carcaça da presença de cisticercos vivos em local que não seja rotineiramente examinado.

De conformidade com os resultados do experimento realizado, conclui-se que não devem ser liberadas para o consumo, sem prévio tratamento pelo frio, pela salga ou calor, carcaças de animais que, na linha de rotina de inspeção, tenham acusado a presença de, pelo menos, um único cisticerco calcificado no conjunto de órgãos e vísceras ou na carcaça.

Os resultados deste experimento, permitem a ilação de que a adoçāo sistemática do tratamento prévio das carcaças enquadradas nas condições descritas, levará a uma diminuição da possibilidade do homem contrair a teníase e, paralelamente, uma minimização ao longo do tempo dos prejuízos econômicos, pela conseqüente redução do número de carcaças condenadas por infecção maciça pelo C. bovis e das destinadas a conserva, salga e mesmo ao congelamento.

Em função das constatações evidenciadas conclui-se por sugerir a reformulação do Art. 176, Parágrafo $2^{\circ}$, Inciso 3 do RIISPOA (1951), em vigor.

É ainda rcomendável que se faça constar explicitamente do RIISPOA o tempo e a temperatura das carnes a serem tratadas pelo frio artificial.

O estudo bibliográfico realizado ao longo do exeprimento leva a recomendar, ainda, à Divisão de Inspeção de Produtos de Origem Animal, do Ministério da Agricultura e Reforma Agrária, o reestudo de sua regulamentação, inclusive quanto a isenção permitida no mesmo artigo 176 , Parágrafo $4^{\circ}$, relativamente à inspeção de animais jovens.

\section{REFERÊNCIAS BIBLIOGRÁFICAS}

ABDUSSALAM, $M$. El problema de la teniasis y la cisticercosis. In: REUNION INTERAMERICANA A NIVEL MINISTERIAL SOBRE EL CONTROL DE LA FIEBRE AFTOSA $Y$ OTRAS ZOONOSIS 1974. Trinidad Tobago, Organ. Mund. Salud, 1974.

ARGENTINA. Ministério da Agricultura y Ganadeira Servicio Nacional de Sanidad Animal. Regulamento de Inspecion de . Productos, SubProductos y Derivados de Origem Animal, decreto $n^{\circ} 4238 / 68$. Buenos Aires, 1971. 251 p.

BRASIL. Decreto $n^{\circ}$ 29.651, de 08 de junho de 1951. Aprova o regulamento de Inspeção Industrial e Sanitária de Produtos de Origem Animal-RIISPOA. Diário Oficial da República Federativa do Brasil, Brasília, V. 90, n. 157, p. 10281,11 jul. 1951. Seção 1. Suplemento.

BRASIL. Decreto no 30.691, de 29 de março de 1952. Aprova o novo Regulamento de Inspeçāo Industrial e Sanitária de Produtos de Origem Animal. Diário Oficia da República Federativa do Brasil, Brasília, v. 91, n. 155, p. 10.785 - 826, 7 jul. 1952. Seção 1.

BRASIL. Decreto no 39.093, de 30 de abril de 1956. Altera o Decreto no 30691/52. Diário Oficial da República Federativa do Brasil, Brasília, v. 95, n. 102, p. 9.106-8, 4 maio 1956. Seção 1.

BRASIL. Decreto no 1.255, de 25 de junho de 1962. Altera o Decreto no $30.691 / 52$. Diario Oficial da República Federativa do Brasil, Brasília, v. 101, n. 125, p. 7.238-45, 4 jul. 1962. Seção 1, Parte 1.

BRASIL. Decreto $n^{\circ}$ 66.183, de 05 de fevereiro de 1970. Revoga o Art. 509 do RIISPOA, com redação dada pelo DCM 1255/1952. Diário Oficial da República Foderativa do Brasil, Brasília, v. 108, n. 26, p. 999-1000, 6 fev. 1970. Seção 1, Parte 1. Retificado no Diário Oficial da República Federativa do Brasil, Brasília, v. 108, n. 31, p. 1202, 17 fev. 1970. Seção 1, Parte 1

BRASIL. Ministério da Agricultura. Serviço de Inspeção de Produtos de Origem Animal. Divisāo de Inspeçāo de Carnes e Derivados. Sumário de Temas Ténicos, Of. $n^{\circ} 01.36$ - 15/9.2, Brasília, 1984.

BRASIL. Ministério da Agricultura. Secretaria Nacional de Defesa Agropecuária. Secretaria de Inspeção de Produto Animal. Condenação de bovinos. Anuário Estatístico. 1986, Brasília, p. 203-244. 
BRASIL Ministério da Agricultura. Serviço de Inspeção de Produto Animal. Delegacia Federal de Agricultura. Boletim Estatística 1989. Porto Alegre, $58 \mathrm{p}$.

CÔRTES, J.A. Epidemiologia do processo teníase humana-cisticercose,Comum Cient Fac Med Vet Zoot Univ S Paulo; v. 8, n. 2, p. 231-241, 1984.

DEPRĖ, P., RUOSCH, W. Diagnostic et importance de la cysticercose bovine em Suisse. Schweizer Arch Tierheilkund, v. 103, n. 10, p. 507-518, 1961.

DEWHIRST, L.W., CRAMER, J.D., SHELDON, J.J. An analisis of current inspection procedures for detecting bovine cysticercosis. J Am Vet Med Ass, v. 150, n. 4, p. 412-417, 1967.

ESTADOS UNIDOS. Meat and Poultry Inspection Regulations. USDA, United States Departament of Agriculture. Food Safety and Inspection Service Washington, D.C., 1979.

EUZEBY, J. Les parasitosis humaines d'origine animale, caracteres epidemiologiques. Paris: Flamarion Medicine Sciences, 1984. 324 p.

GINSBERG, A. Helminthic zoonoses in meat inspection. Bul Epi Dis Africa, v. 6, p. 141-149, 1958.

GINSBERG. The detection of Cysticercus bovis in the abattoir. Vet Rec,. v. 72, n. 6, p. 310, 1960.

JURANEK, D.D., FORBES, L.S., KELLER, U. Taөnia saginata Cysticerci in muscles of beef cattle. Am J Vet Res, v. 37, n. 7, p. 785-789, 1976.

LAZZARO, D.A. Cisticercosis bovina. Gaceta Veterinária Buenos aires, v. 23, p. 19-21, 1961.

MARSHBOOM, R., VAN PARIS, O., BRODSKY, $M$. Contribution à l'étude des localisations preferentielles des cysticerques chez les gros bétail in Urundi. Annls Med Vet, v. 104, p. 191-196, 1960.

MCCOOL, C.J. Distribuition of Cysticercus bovis in lightly infected young cattle. Aust vet J, v. 55, p. 214-221, 1979.

MCMANUS, D. Prenatal infection of calves with Cysticercus bovis. Vet Rec, v. 47, p. 977-979, 1963.
NADZHAROVL, I.G., MAMEDOV, R.G., SHIKHALEV, SH.I. Intrauterine infection with cysticercosis of calves and the role of this factor in epidemiology of Taenia saginata infection. Medi Parasitol Parazit Bol, v. 1, p. 74-77, 1985.

RICKARD, M.D., ADOLPH, A.J. The prevalence of cysticerci Taenia saginata in cattle reared on sewage irrigated pasture. Med J Aust, v. 1, p. 525-527, 1977.

SANTOS, I.F. Diagnóstico da Cisticercose bovina em matadouros: Novas tecnicas de exame de esófago e diafragma. São Paulo, 1984, 127 p. Tese (Doutorado em Saúde Pública). Universidade de São Paulo. 1984.

SGAMBATI, A. La cisticercosi bovina nelle sue localizzazioni. Zooprofilassi, v. 50, p. 679-687, 1959.

SILVERMANN, P.H. "Predilection sites" for Cysticercus bovis in cattle. Trans R Soc Trop Med Hyg, v. 50, p. 7, 1956.

THAKUR, A.S. Teniasis y cisticercoses. Buenos Aires, 1984. Mimeografado.

UNGAR, M.L. Prevalência da cisticercose bovina (Cysticercus bovis Goeze, 1782) do Estado de São Paulo, detectada em matadouros do referido Estado, sob o controle do serviço de Inspeção Federal, no ano de 1986. São Paulo, 1990. 199 p.Tese de Mestrado em Medicina Veterinária e Zootecnia. (Epidemiologia Experimental e Aplicada a Zoonoses). Universidade de São Paulo.

URUGUAY. Ministério de Agricultura y Pesca Direccion General de los Servicios Veterinários. Regulamento Oficial de Inspeccion Veterinária de Productos de Origem Animal, Montevideo, 1983. 121 p. Parte 1: Carne Subproductos, derivados y Productos carnicos, Decreto 369,983 del 7 de octubre de 1983.

WALTHER, M., KOSKE, J.K. Taenia saginata cysticercosis: A comparison of routine meat inspection and carcass dissection results. Vet Rec, v. 106, p. 401-402, 1980. 